\title{
Warfarin reduced major stroke more than aspirin in elderly patients with atrial fibrillation in primary care.
}

Mant J, Hobbs FDR, Fletcher K, et al. Warfarin versus aspirin for stroke prevention in an elderly community population with atrial fibrillation (the Birmingham Atrial Fibrillation Treatment of the Aged Study, BAFTA): a randomised controlled trial. Lancet 2007;370:493-503.

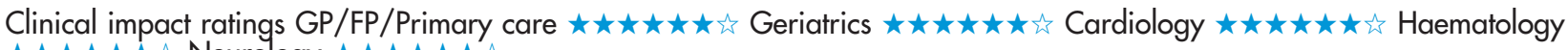

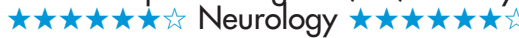

In elderly patients with atrial fibrillation (AF) in primary care, is warfarin more effective than aspirin for preventing major stroke, arterial embolism, and intracranial haemorrhage?

\section{METHODS}

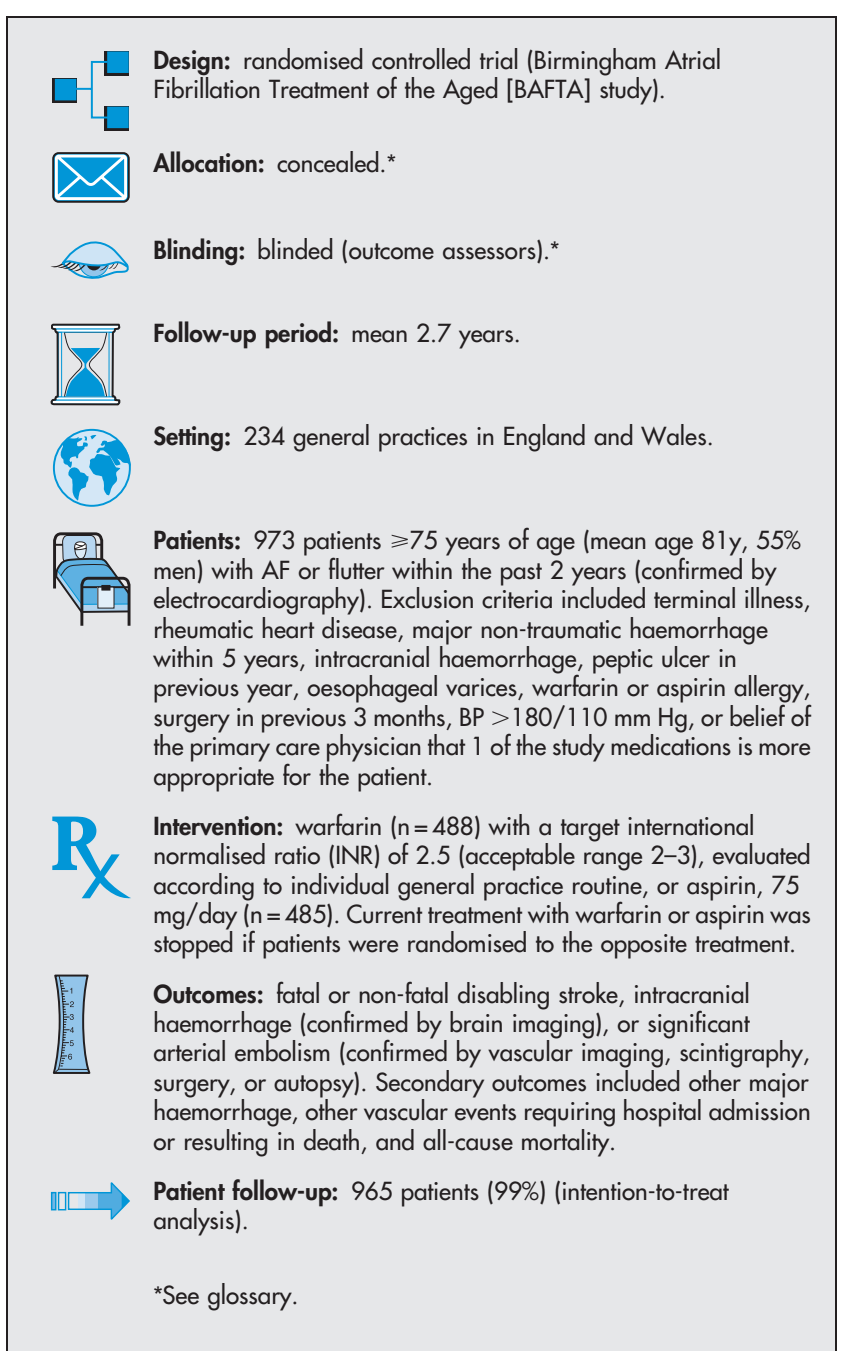

\section{MAIN RESULTS}

At a mean follow-up of 2.7 years, the incidence of major stroke, other intracranial haemorrhage, or systemic embolism was lower in the warfarin group than the aspirin group (table). All-cause mortality (8.0\% $v 8.4 \%$ per $y$, respectively) and major haemorrhage $(1.9 \% v$ $2.0 \%$ per $y$, respectively) were similar for both groups, although the trial was not powered to detect group differences for those outcomes.

For correspondence: Dr J Mant and Professor R Hobbs, University of Birmingham, Birmingham, UK; j.w.mant@bham.ac.uk Source of funding: Medical Research Council (MRC).

\section{CONCLUSION}

In patients $\geqslant 75$ years of age with atrial fibrillation in primary care, warfarin was more effective than aspirin for reducing major stroke.

Abstract and commentary also appear in ACP Journal Club.

Warfarin $v$ aspirin for preventing stroke in patients $\geqslant 75$ years of age with atrial fibrillation*

\begin{tabular}{lllll}
$\begin{array}{l}\text { Outcome at mean } \\
\text { 2.7 years }\end{array}$ & Warfarin & Aspirin & RRR (95\% CI) & NNT (CI) \\
\hline $\begin{array}{l}\text { Major stroke, } \\
\text { intracranial } \\
\text { haemorrhage, or } \\
\text { systemic embolism† }\end{array}$ & $4.9 \%$ & $9.9 \%$ & $50 \%$ & 21 \\
& & & & \\
\hline
\end{tabular}

*Abbreviations defined in glossary. RRR, NNT, and Cl calculated from data in article.

† Major stroke $(4.3 \% \vee 9.1 \%)$, other intracranial haemorrhage $(0.4 \% v$ $0.2 \%)$, and systemic embolism $(0.2 \% \vee 0.6 \%)$.

\section{Commentary}

$\Lambda$ $\mathrm{F}$ is the most common arrhythmia in the elderly and is a strong independent risk factor for stroke. Warfarin remains underutilised in the elderly despite the fact that age independently predicts stroke risk in $A F^{1}{ }^{\prime}$ A recent meta-analysis of adjusted dose warfarin compared with placebo in AF showed a relative risk reduction (RRR) of $64 \%$ and absolute risk reduction (ARR) of $2.7 \%$ /year for stroke with warfarin. ${ }^{2}$ In the same meta-analysis, adjusted dose warfarin compared with antiplatelet therapy had an RRR of $37 \%$ and an ARR of $0.9 \% / y e a r$. Absolute increases in major extracranial haemorrhage with warfarin were small (about $0.3 \% / y$ ). A limitation of prior randomised trials has been the under-representation of the elderly. The BAFTA study is a step forward in helping to convince clinicians that warfarin dosed to a target INR of 2.5 in the elderly is more effective in preventing stroke and systemic embolism than aspirin. Although the study was not powered to detect a difference in major bleeding, a low rate of such bleeding in both groups is somewhat reassuring.

Study features that make the results more generalisable to the elderly include enrolment from primary care practices, mean age of 81 years, $\mathrm{CHADS}_{2}$ score of 1 or $2^{3}$ in $>70 \%$ of patients, blinded outcome assessment, and a fair amount of crossover between groups. The aspect that makes this study less generalisable is that $>50 \%$ of the patients were managed by hospital run anticoagulation clinics, which are better than individual doctors in managing INR and, therefore, may be a reason for the high rate of therapeutic INRs and the low rate of bleeding.

The BAFTA study results would support adjusted dose warfarin with a target INR of 2.5 (range $2-3$ ) for all patients $\geqslant 75$ years with $A F$ in the absence of contraindications. This recommendation is more liberal than the current referenced guidelines. ${ }^{1} 34$

Amir K Jaffer, MD Leonard M Miller School of Medicine University of Miami, Miami, Florida, USA

1 Fuster V, Rydén LE, Cannom DS, et al. Circulation 2006;114:e257-354.

2 Hart RG, Pearce LA, Aguilar MI. Ann Intern Med 2007; 146:857-67.

3 Gage BF, Waterman AD, Shannon W, et al.JAMA 2001;285:2864-70.

4 Snow V, Weiss KB, LeFevre M, et al.Ann Intern Med 2003;139:1009-17. 